\title{
Terpolymer approach for controlling the crystalline behavior of naphthalene diimide-based polymer acceptors and enhancing the performance of all-polymer solar cells
}

\author{
Youngwoong Kim ${ }^{1}$, Han-Hee $\mathrm{Cho}^{1}$, Taesu Kim ${ }^{1}$, Kin $\mathrm{Liao}^{2}$ and Bumjoon J Kim ${ }^{1}$ \\ A new series of $n$-type D-A terpolymers (P(NDI2HD-T-S)) was synthesized from an electron-deficient naphthalene diimide \\ (NDI)-based unit in conjugation with two electron-rich thiophene (T) and selenophene (S) units, and their performances as \\ electron acceptors in all-polymer solar cells (all-PSCs) were compared. The crystallinity of the P(NDI2HD-T-S) terpolymers \\ can be systematically controlled by tuning the $T / S$ molar ratios $(T / S=100 / 0,80 / 20,50 / 50,20 / 80$ and $0 / 100)$ in the polymer \\ backbone. An increase in the $\mathrm{S}$ content induced a significant enhancement in the crystallinity of the terpolymers. Therefore, the \\ incorporation of more $\mathrm{S}$ units enhanced the structural ordering of the terpolymers and the electron mobility in the all-PSCs. The \\ power conversion efficiency of the all-PSCs based on a P(NDI2HD-T-S) terpolymer acceptor and a PTB7 polymer donor increased \\ from 2.50 to $3.60 \%$ as the $S$ content increased, which was primarily due to the enhanced short-circuit current. To understand \\ the effects of the T/S compositions on the photovoltaic performances, we investigated their influence on the optical, electrical \\ and structural properties of the n-type D-A terpolymers.
}

Polymer Journal (2016) 48, 517-524; doi:10.1038/pj.2016.22; published online 17 February 2016

\section{INTRODUCTION}

Organic photovoltaics have attracted much attention as an alternative energy source for decades, and their power conversion efficiency (PCE) has been increased to $10 \%$ for bulk heterojunction (BHJ) solar cells consisting of polymer donor and fullerene derivative as the acceptor. ${ }^{1-8}$ Although fullerene derivatives possess great potential as electron acceptors due to their high electron affinity and high electron mobility, fullerenes, such as the most widely used phenyl- $\mathrm{C}_{61}$ butyric acid methyl ester, are not ideal acceptor materials due to several intrinsic drawbacks, such as high synthetic cost and low light absorption in the visible regime. ${ }^{9-12}$ Moreover, fullerene-based organic photovoltaics have poor flexibility and tensile properties due to the brittle crystalline features of the fullerenes. ${ }^{13-15}$

Recently, all-polymer solar cells (all-PSCs), which comprise binary blends of conjugated polymer donors/polymer acceptors, have attracted significant interest due to their advantages over conventional fullerene-based organic photovoltaics. These advantages include (i) easy tuning of frontier energy levels of the polymer acceptor, (ii) simultaneous absorption of both the polymer donor and the polymer acceptor and (iii) outstanding mechanical/thermal properties. ${ }^{16-27}$ In particular, naphthalene diimide (NDI)-based polymer acceptors have highly planar structures, good electron mobility and good compatibility with polymer donors, making them promising alternative materials to fullerenes. ${ }^{18,23,28,29}$ However, n-type polymer acceptors typically have a much lower electron mobility than that of fullerenes. In addition, their packing orientation in a thin film should be carefully controlled to enhance the short-circuit current $\left(J_{S C}\right)$ and fill factor $(\mathrm{FF})$ values of all-PSCs. ${ }^{15,18,30}$

The use of terpolymers, which contain three different units in the polymer backbone, provides an effective approach for modulating the physical and opto-electronic properties of the D-A-type conjugated polymers. ${ }^{31-38}$ Importantly, the crystalline behaviors of conjugated polymers and their packing structures in thin films can be controlled using the terpolymer approach, which would be particularly important for enhancing the electron mobility of the polymer acceptor and producing all-PSCs with a high performance. ${ }^{38,39}$ The incorporation of selenophene into terpolymers could significantly improve their intermolecular interactions and induce highly ordered polymer assembly due to better orbital overlap between the polymers resulting from the preferred formation of quinoidal structures of selenophenes rather than the formation of aromatic structures. ${ }^{36,40,41}$ Therefore, the insertion of selenophenes into the $\pi$-conjugated backbone could be advantageous for charge transport by facilitating interchain charge transfer. ${ }^{42}$ For example, varying the thiophene (T)/selenophene (S)

\footnotetext{
${ }^{1}$ Department of Chemical and Biomolecular Engineering, Korea Advanced Institute of Science and Technology (KAIST), Daejeon, Korea and ${ }^{2}$ Department of Mechanical Engineering, Khalifa University, Abu Dhabi, United Arab Emirates

Correspondence: Professor BJ Kim, Department of Chemical and Biomolecular Engineering, Korea Advanced Institute of Science and Technology (KAIST), Buidling W1-3, Rm 6101, Daejeon 305-701, Korea.

E-mail: bumjoonkim@kaist.ac.kr

Received 30 November 2015; revised 21 January 2016; accepted 22 January 2016; published online 17 February 2016
} 
ratio in diketopyrrolopyrrole-based terpolymers altered their crystalline behaviors, resulting in an optimal point between crystallinity and solubility with further enhanced efficiency. ${ }^{36}$ Very recently, Jenekhe's group reported a highly efficient NDI-selenophene-based all-PSC with a PCE of $7.7 \%$, indicating the potential of the selenophene unit for use in all-PSCs. ${ }^{43}$ However, very limited examples of $n$-type terpolymer acceptors have been reported. ${ }^{31-33,44}$ In addition, the effect of the incorporation of the selenophene unit into n-type polymers on their structural, electrical and photovoltaic properties remains unclear.

In this study, we report a series of NDI-based random terpolymers (P(NDI2HD-T-S) ) based on one electron-deficient NDI unit and two electron-rich units of $\mathrm{T}$ and $\mathrm{S}$ to study the effect of the $\mathrm{T} / \mathrm{S}$ composition on the optical, structural and electronic properties. The NDI was copolymerized with varying amounts of $\mathrm{T}$ and $\mathrm{S}$ monomers to produce $\mathrm{P}(\mathrm{NDI} 2 \mathrm{HD}-\mathrm{T}-\mathrm{S})$ terpolymers with different T/S compositions $(100 / 0,80 / 20,50 / 50,20 / 80$ and 0/100) in the polymer backbone. As the selenophene content in the polymer backbone increased, the crystallinity of the terpolymers was significantly enhanced. In addition, the polymer packing structure and charge transport through the intermolecular chains were enhanced due to the increased crystallinity. Therefore, the all-PSCs consisting of a poly[[4,8-bis[(2-ethylhexyl)oxy] benzo[1,2-b:4,5-b'] dithiophene-2,6-diyl] [3-fluoro-2-[(2-ethylhexyl) carbonyl]thieno[3,4-b]thiophenediyl]] (PTB7) donor and a $\mathrm{P}$ (NDI2HD-T-S) acceptor exhibited PCEs that increased from 2.50 to $3.60 \%$ with enhanced $J_{\mathrm{SC}}$ values as the selenophene content increased. The results from grazing-incidence X-ray scattering (GIXS) and atomic force microscopy (AFM) confirmed the formation of a highly ordered interchain packing structure for P(NDI2HD-T-S) with a higher selenophene content, inducing a more distinct fibril structure in the intermixed $\mathrm{BHJ}$ morphology.

\section{MATERIALS AND METHODS}

\section{Materials}

4,9-Dibromo-2,7-bis(2-hexyldecyl)benzo[ $\operatorname{lmn}][3,8]$-phenanthroline-1,3,6,8-tetraone (NDI2HD) was purchased from Sunatech Inc. (Suzhou, Jiangsu, China). 2,5-Bis(trimethylstannyl)-thiophene and 2,5-bis(trimethylstannyl)-selenophene were synthesized according to the previously reported procedures. ${ }^{36}$ PTB7 (the number-average molecular weight $\left(M_{\mathrm{n}}\right)=14 \mathrm{~kg} \mathrm{~mol}^{-1}$, weight-average molecular weight $\left(M_{\mathrm{w}}\right)=28 \mathrm{~kg} \mathrm{~mol}^{-1}$, polydispersity index $\left.(\mathrm{PDI})=1.94\right)$ was purchased from 1 Materials Inc. (Dorval, Québec, Canada). The other chemicals were purchased from Sigma-Aldrich and used without further purification.

General polymerization procedure using the Stille coupling reaction All of the polymers were synthesized via a Stille coupling reaction under microwave irradiation. All of the monomers were weighed and placed in a vial for the microwave reaction. Tri $(o$-tolyl $)$ phosphine $\left(\mathrm{P}(o-\mathrm{tol})_{3}, 8 \mathrm{~mol} \%\right)$ and tris (dibenzylideneacetone)dipalladium $\left(\mathrm{Pd}_{2}(\mathrm{dba})_{3}, 2 \mathrm{~mol} \%\right)$ were also weighed and added. The vial was equipped with a magnetic stirrer and capped. Anhydrous toluene and anhydrous $\mathrm{N}, \mathrm{N}$-dimethylformamide (DMF) were injected, and the solution was degassed with argon for $30 \mathrm{~min}$. The vial was placed in a microwave reactor and reacted for $3 \mathrm{~h}$ at $150^{\circ} \mathrm{C}$. After cooling to room temperature, the product was precipitated into a solution consisting of $250 \mathrm{ml}$ of methanol and $5 \mathrm{ml}$ of hydrochloric acid followed by stirring for $2 \mathrm{~h}$. The resulting solids were sequentially purified via Soxhlet extraction using methanol, acetone, hexane, and chloroform. The chloroform fraction was concentrated under reduced pressure and precipitated into methanol. The polymer was dried under vacuum for $24 \mathrm{~h}$.

\section{Polymerization for $\mathrm{P}\left(\mathrm{NDI} 2 \mathrm{HD}-\mathrm{T}_{100}\right)$ (P1)}

A mixture of NDI2HD (1.0 equiv.) and 2,5-bis(trimethylstannyl)thiophene (1.0 equiv.) in toluene and DMF was used to synthesize P1 using the previously mentioned general procedure. Size exclusion chromatography (SEC) (chloroform fraction): $M_{\mathrm{n}}=54 \mathrm{k}, M_{\mathrm{w}}=114 \mathrm{k}, \mathrm{PDI}=2.10$. Elem. anal. calcd.: C, 75.33; H, 9.10; N, 3.51; S, 4.02. Found: C, 74.68; H, 8.97; N, 3.42; S, 4.00.

\section{Polymerization for $\mathrm{P}\left(\mathrm{NDI} 2 \mathrm{HD}-\mathrm{T}_{\mathbf{8 0}} \mathrm{S}_{\mathbf{2 0}}\right)$ (P2)}

A mixture of NDI2HD (1.0 equiv.), 2,5-bis(trimethylstannyl)thiophene ( 0.8 equiv.) and 2,5-bis(trimethylstannyl)selenophene ( 0.2 equiv.) in toluene and DMF was used to synthesize $\mathbf{P} 2$ using the previously mentioned general procedure. SEC (chloroform fraction): $M_{\mathrm{n}}=74 \mathrm{k}, M_{\mathrm{w}}=154 \mathrm{k}, \mathrm{PDI}=2.08$. Elem. anal. calcd.: C, 74.61; H, 8.82; N, 3.48; S, 3.19. Found: C, 74.12; H, 8.85; $\mathrm{N}, 3.34$; S, 3.04 .

\section{Polymerization for $\mathrm{P}\left(\mathrm{NDI} 2 \mathrm{HD}-\mathrm{T}_{50} \mathrm{~S}_{50}\right)$ (P3)}

A mixture of NDI2HD (1.0 equiv.), 2,5-bis(trimethylstannyl)thiophene (0.5 equiv.) and 2,5-bis(trimethylstannyl)selenophene ( 0.5 equiv.) in toluene and DMF was used to synthesize $\mathbf{P} 3$ using the previously mentioned general procedure. SEC (chloroform fraction): $M_{\mathrm{n}}=53 \mathrm{k}, M_{\mathrm{W}}=112 \mathrm{k}, \mathrm{PDI}=2.10$. Elem. anal. calcd.: C, 73.27; H, 8.73; N, 3.42; S, 1.96. Found: C, 73.72; H, 8.74; $\mathrm{N}, 3.38 ; \mathrm{S}, 1.90$.

\section{Polymerization for $\mathrm{P}\left(\mathrm{NDI} 2 \mathrm{HD}-\mathrm{T}_{\mathbf{2 0}} \mathrm{S}_{\mathbf{8 0}}\right)$ (P4)}

A mixture of NDI2HD (1.0 equiv.), 2,5-bis(trimethylstannyl)thiophene ( 0.2 equiv.) and 2,5-bis(trimethylstannyl)selenophene ( 0.8 equiv.) in toluene and DMF was used to synthesize $\mathbf{P} 4$ using the previously mentioned general procedure. SEC (chloroform fraction): $M_{\mathrm{n}}=69 \mathrm{k}, M_{\mathrm{w}}=147 \mathrm{k}, \mathrm{PDI}=2.13$. Elem. anal. calcd.: C, 72.09; H, 8.52; N, 3.36; S, 0.77. Found: C, 73.04; H, 8.64; $\mathrm{N}, 3.32 ; \mathrm{S}, 0.73$.

\section{Polymerization for $\mathrm{P}\left(\mathrm{NDI} 2 \mathrm{HD}-\mathrm{S}_{100}\right)$ (P5)}

A mixture of NDI2HD (1.0 equiv.) and 2,5-bis(trimethylstannyl)selenophene (1.0 equiv.) in toluene and DMF was used to synthesize P5 using the previously mentioned general procedure. SEC (chloroform fraction): $M_{\mathrm{n}}=67 \mathrm{k}$, $M_{\mathrm{w}}=160 \mathrm{k}, \mathrm{PDI}=2.40$. Elem. anal. calcd.: C, $71.15 ; \mathrm{H}, 8.60 ; \mathrm{N}, 3.32 ; \mathrm{S}$, 0.00. Found: C, $71.82 ; \mathrm{H}, 8.52 ; \mathrm{N}, 3.30 ; \mathrm{S}, 0.00$.

\section{Characterizations}

The ${ }^{1} \mathrm{H}$-NMR spectra were obtained on a Bruker $300 \mathrm{MHz}$ NMR instrument using $\mathrm{CDCl}_{3}$ or $o$-dichlorobenzene- $d_{4}$ as a solvent. The $M_{\mathrm{n}}, M_{\mathrm{w}}$ and PDI of the polymers were measured using SEC at $80^{\circ} \mathrm{C}$ with a flow rate of $1 \mathrm{ml}$ per min, and the SEC instrument was equipped with a Waters 1515 Isocratic HPLC pump, a temperature control module, and a Waters 2414 refractive index detector. $o$-Dichlorobenzene (o-DCB) was used as an eluent with polystyrene standards. The UV-visible (UV-vis) absorption spectra were measured from dilute solutions $\left(10^{-6} \mathrm{M}\right)$ in chloroform and solid-state films with a UV-1800 spectrophotometer (Shimadzu Scientific Instruments) at room temperature. Cyclic voltammetry (CV) measurements were carried out with a CHI $600 \mathrm{C}$ electro-chemical analyzer using a Pt disk working electrode, a Pt counter electrode and an Ag wire quasi-reference electrode. The CV experiments were conducted in anhydrous acetonitrile containing $0.1 \mathrm{M}$ tetrabutylammonium hexafluorophosphate $\left(\mathrm{Bu}_{4} \mathrm{NPF}_{6}\right.$ ) (a potential scan rate: $50 \mathrm{mV} \mathrm{s}{ }^{-1}$ ). GIXS was performed at the beamline in the Pohang Accelerator Laboratory (South Korea). The GIXS samples were prepared by spin coating onto a Si substrate. X-rays with a wavelength of $1.1179 \AA$ were employed. The incidence angle $\left(\sim 0.12^{\circ}\right)$ was selected to allow for complete penetration into the film. AFM measurements were performed using a Veeco Dimension 3100 instrument in tapping mode.

\section{Device fabrication and measurements}

Inverted-type all-PSCs were fabricated with a ITO/ZnO/PTB7:terpolymer/ $\mathrm{MoO}_{3} / \mathrm{Ag}$ structure. The $\mathrm{ZnO}$ sol-gel was prepared using a sol-gel procedure, which involved dissolving zinc acetate dihydrate $\left(\mathrm{Zn}\left(\mathrm{O}_{2} \mathrm{CCH}_{3}\right)_{2} \bullet\left(\mathrm{H}_{2} \mathrm{O}\right)_{2}\right.$, $99.9 \%, 1 \mathrm{~g})$ and ethanolamine $\left(\mathrm{HOCH}_{2} \mathrm{CH}_{2} \mathrm{NH}_{2}, 99.5 \%, 0.28 \mathrm{~g}\right)$ in anhydrous 2-methoxy ethanol $\left(\mathrm{CH}_{3} \mathrm{OCH}_{2} \mathrm{CH}_{2} \mathrm{OH},>99.8 \%, 10 \mathrm{ml}\right)$ under vigorous stirring for more than $24 \mathrm{~h}$ for the hydrolysis reaction and aging. The sol-gel type of $\mathrm{ZnO}$ was used and spin coated on the ITO substrate at 3000 r.p.m. for 40 s. The films were heated at $200{ }^{\circ} \mathrm{C}$ for $10 \mathrm{~min}$ in air. After that, all of the procedures were conducted in a glove box under an $\mathrm{N}_{2}$ 
atmosphere. Each blending solution using chloroform as a solvent and 1,8-diiodooctane (DIO) as an additive (PTB7:P(NDI2HD-T-S) $=1.3: 1 \mathrm{w} / \mathrm{w}$, polymer concentration $=12 \mathrm{mg} \mathrm{ml}^{-1}$, DIO additive $=1 \mathrm{vol} \%$ ) was spin coated onto an ITO/ZnO substrate at 3000 r.p.m. for 40 s. Finally, the electrodes consisting of $10 \mathrm{~nm} \mathrm{MoO}_{3}$ and a $120 \mathrm{~nm} \mathrm{Ag}$ film were thermally evaporated under high vacuum $\left(<10^{-6}\right.$ Torr $)$. The active area of the fabricated device was $0.09 \mathrm{~cm}^{2}$, which was carefully measured using an optical microscope. The current density-voltage $(J-V)$ characteristics of the devices were measured under simulated AM 1.5G solar irradiation $\left(100 \mathrm{~mW} \mathrm{~cm}^{-2}\right.$, Peccell: PEC-L01) at ambient conditions. This solar simulator system satisfies the Class AAB, ASTM Standards. The intensity of the solar simulator was carefully calibrated using a standard silicon reference cell with a KG-5 visible color filter. The $J-V$ behavior was recorded using a Keithley 2400 SMU.

\section{RESULTS AND DISCUSSION}

Synthesis and characterization

In this study, two parent alternating copolymers (that is, PNDI2HD$\mathrm{T}_{100}(\mathbf{P 1})$ and PNDI2HD-S 100 (P5)) and three random P(NDI2HD$\mathrm{T}-\mathrm{S})$ terpolymers were prepared by controlling the feed molar ratios of the $\mathrm{T}$ and $\mathrm{S}$ monomers in the Stille coupling reaction (Figure 1). ${ }^{36}$ Different $T / S$ ratios $(T / S=80 / 20,50 / 50$ and $20 / 80$ ) were used to

a
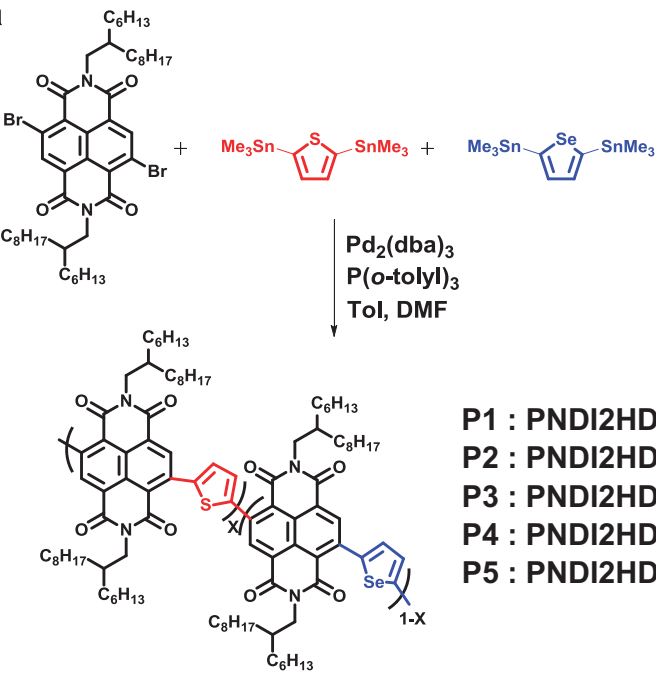

P1 : PNDI2HD-T 100

$\mathrm{P} 2$ : PNDI2HD- $\mathrm{T}_{80} \mathrm{~S}_{20}$

$\mathrm{P3}$ : PNDI2HD- $\mathrm{T}_{50} \mathrm{~S}_{50}$

P4 : PNDI2HD-T ${ }_{20} \mathrm{~S}_{80}$

P5 : PNDI2HD-S 100

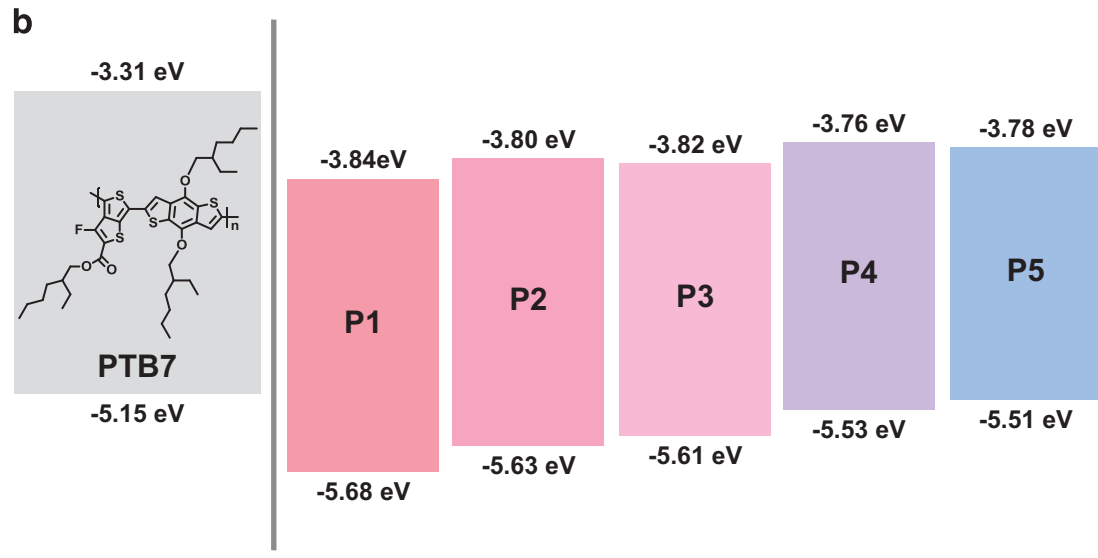

Figure 1 (a) Synthetic route and structures of the P(NDI2HD-T-S) terpolymers. (b) Energy level diagrams for P1-P5 and PTB7.

Table 1 Characteristics of P(NDI2HD-T-S) terpolymers

\begin{tabular}{|c|c|c|c|c|c|c|}
\hline Polymers & $\mathrm{M}_{n} \mathrm{M}_{w}\left(\mathrm{~kg} \mathrm{~mol}^{-1}\right)^{\mathrm{a}}$ & $P D /\left(\mathrm{M}_{\mathrm{w}} \mathrm{M}_{\mathrm{n}}\right)^{\mathrm{a}}$ & $\lambda_{\max }{ }^{\text {Film }}(n m)^{\mathrm{b}}$ & HOMO $(\mathrm{eV})^{\mathrm{C}}$ & LUMO (eV)d & $\mathrm{E}_{g}{ }^{o p t}(\mathrm{eV})^{\mathrm{e}}$ \\
\hline $\mathrm{P}\left(\mathrm{NDI} 2 \mathrm{HD}-\mathrm{T}_{100}\right)(\mathrm{P} 1)$ & $54 / 114$ & 2.10 & 343,599 & -5.68 & -3.84 & 1.84 \\
\hline $\mathrm{P}\left(\mathrm{NDI} 2 \mathrm{HD}-\mathrm{T}_{80}-\mathrm{S}_{20}\right)(\mathbf{P} 2)$ & $74 / 154$ & 2.08 & 346,607 & -5.63 & -3.80 & 1.83 \\
\hline $\mathrm{P}\left(\mathrm{NDI} 2 \mathrm{HD}-\mathrm{T}_{50}-\mathrm{S}_{50}\right)(\mathrm{P} 3)$ & $53 / 112$ & 2.10 & 349, 609 & -5.61 & -3.82 & 1.79 \\
\hline $\mathrm{P}\left(\mathrm{NDI} 2 \mathrm{HD}-\mathrm{T}_{20}-\mathrm{S}_{80}\right)(\mathbf{P} 4)$ & $69 / 147$ & 2.13 & 355,620 & -5.53 & -3.76 & 1.77 \\
\hline P(NDI2HD-S 100$)(P 5)$ & $67 / 160$ & 2.40 & 357,627 & -5.51 & -3.78 & 1.73 \\
\hline
\end{tabular}

Abbreviations: HOMO, highest occupied molecular orbital; LUMO, lowest unoccupied molecular orbital; PDI, polydispersity index.

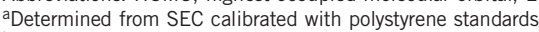

betermined from UV-vis measurements.

${ }^{C}$ Estimated by subtracting the $E_{\mathrm{g}}{ }^{\mathrm{opt}}$ from the CV-determined LUMO levels.

dMeasured by $\mathrm{CV}$ measurements.

eCalculated from the absorption onset in film. 
produce $\mathrm{P}\left(\mathrm{NDI} 2 \mathrm{HD}-\mathrm{T}_{80} \mathrm{~S}_{20}\right) \quad(\mathbf{P} 2), \quad \mathrm{P}\left(\mathrm{NDI} 2 \mathrm{HD}-\mathrm{T}_{50} \mathrm{~S}_{50}\right) \quad(\mathbf{P} 3)$ and $\mathrm{P}\left(\mathrm{NDI} 2 \mathrm{HD}-\mathrm{T}_{20} \mathrm{~S}_{80}\right)$ (P4). All of the polymers were obtained by precipitating the chloroform fraction in methanol after Soxhlet extraction with methanol, acetone, hexane and chloroform. The $M_{\mathrm{n}}$, $M_{\mathrm{w}}$ and PDI of P1-P5 were measured by SEC with $o$-DCB as the eluent at $80^{\circ} \mathrm{C}$. The characteristics of the terpolymers are summarized in Table 1. All of the polymers exhibited high $M_{\mathrm{n}}$ values of $53-74 \mathrm{~kg} \mathrm{~mol}^{-1}$ and similar PDI values in the 2.1-2.4 range, which minimized the effects of the molecular weight on the various properties of the polymers. To determine the actual T/S ratio in the polymer backbone, P1-P5 were characterized by NMR and elemental analysis

a
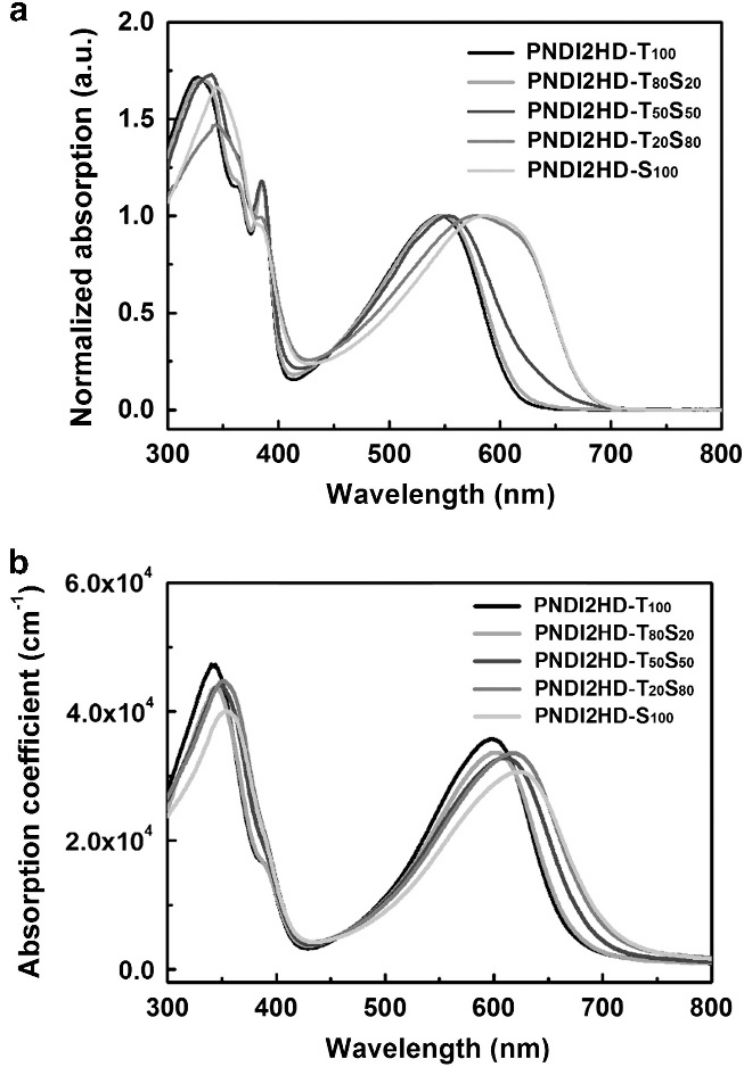

Figure 2 UV-vis absorption spectra of the P(NDI2HD-T-S) terpolymers in (a) diluted chloroform solutions and (b) thin films. A full color version of this figure is available at Polymer Journal online.

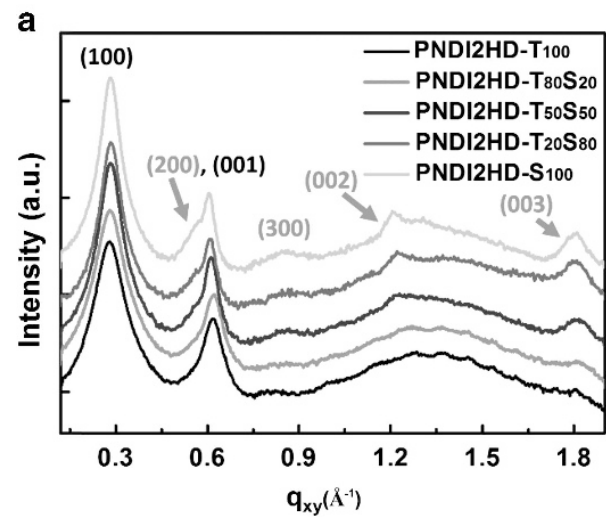

(EA) (Supplementary Table S1 and Supplementary Figure S1 in the Supplementary Information). The actual T/S ratios in the copolymers were determined by comparing the integrations of the peaks corresponding to $\mathrm{T}$ (7.56 p.p.m.) and S (7.74 p.p.m.) (Supplementary Figure $\mathrm{S} 1$ ). In addition, the T/S ratios from EA were obtained by comparing the ratios of carbon atoms to sulfur atoms in the terpolymers. The actual ratios of the copolymers based on the NMR and EA results are listed in Supplementary Table S2 and in good agreement with the feed ratio within the experimental error.

\section{Optical and electrochemical properties}

The optical properties of the polymers in diluted chloroform solutions and thin films are shown in Figure 2. In the solid state, all of the terpolymers exhibited similar absorption in a range from 300 to $700 \mathrm{~nm}$, and the maximum absorption peaks $\left(\lambda_{\max }\right)$ were red-shifted slightly from P1 to P5 as the selenophene content increased (Table 1). However, the vibronic peaks due to the pre-aggregation of the polymers in the solution state began to appear for P3, and these peak intensities increased substantially for $\mathbf{P 4}$ and $\mathbf{P 5}$, indicating that the incorporation of the selenophene unit enhanced the intermolecular assembly of the terpolymers. The optical energy band gaps $\left(E_{\mathrm{g}}{ }^{\text {opt }}\right)$ based on the onset of light absorption for P1-P5 were estimated to be $1.84,1.83,1.79,1.77$ and $1.73 \mathrm{eV}$, respectively. The energy levels of the lowest unoccupied molecular orbital (LUMO) of the polymers were determined by CV with a ferrocene/ferrocenium reference (Supplementary Figure S2). In addition, the energy levels of the highest occupied molecular orbital (HOMO) of the polymers were calculated by subtracting $E_{\mathrm{g}}^{\mathrm{opt}}$ from the CV-determined LUMO levels (Table 1). ${ }^{45}$ The LUMO levels of the terpolymers were similar (that is, c.a. $-3.8 \mathrm{eV}$ ). However, the HOMO levels increased gradually as the selenophene content increased in the following order: -5.68 (P1), -5.63 (P2), -5.61 (P3), $-5.53(\mathbf{P 4})$ and $-5.51 \mathrm{eV}(\mathbf{P 5})$.

\section{Structural properties of pristine films}

To investigate the effect of the selenophene unit on the crystalline behavior and microstructure of five different polymers, GIXS measurements of the pristine P1-P5 films were performed (Supplementary Figure S3). All of the films were prepared under identical conditions by spin coating from chloroform solutions without any treatments. Figure 3 shows the in-plane $\left(q_{x y}\right)$ and out-of-plane $\left(q_{z}\right)$ line cuts of the GIXS images for the pristine terpolymer films. All five polymers exhibited intrinsic (100) reflection peaks in the $q_{x y}$ direction with similar lamellar spacings $\left(d^{100}\right)$ of $2.21-2.24 \mathrm{~nm}$ (Table 2). In addition, the (001) reflection peaks caused by the

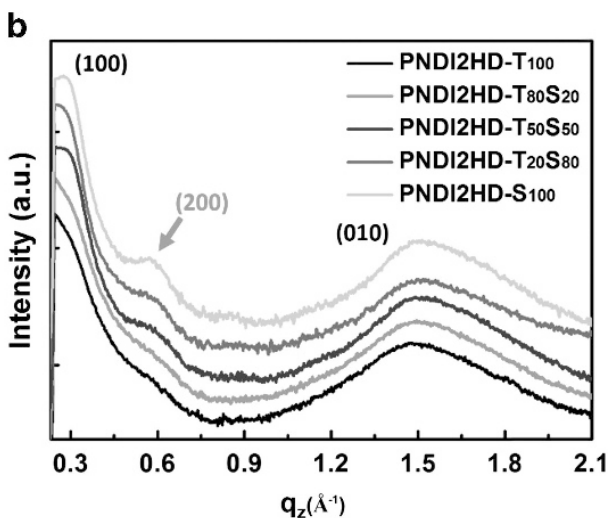

Figure 3 (a) In-plane line and (b) out-of-plane line cuts of the GIXS images for pristine P(NDI2HD-T-S) terpolymer films. A full color version of this figure is available at Polymer Journal online. 
repeating NDI units in the polymer backbone were observed for all of the terpolymers. The (010) reflection peaks corresponding to the $\pi-\pi$ stacking in the $q_{z}$ direction decreased from $0.415 \mathrm{~nm}(\mathbf{P 1})$ to $0.405 \mathrm{~nm}$ (P5) as the selenophene content increased due to better orbital overlap between the molecular chains. The $\pi-\pi$ stacking is more prominent in the out-of-plane direction, which is important for producing efficient charge transport between the electrodes of the all-PSCs. ${ }^{46}$ Interestingly, as the selenophene content increased, the (200) and (300) highorder reflection peaks began to appear in both the $q_{x y}$ and $q_{z}$ directions, and the width of the (100) peak became simultaneously sharper. The correlation lengths $\left(L_{C}\right)$ of the five polymers in the pristine films were calculated from full widths at half maximums of the scattering peaks using the Scherrer equation (Table 2). ${ }^{47}$ The $L_{C}{ }^{100}$ values of P1-P5 increased gradually from 9.63 (P1) to 9.86 (P2), 13.14

Table 2 Crystalline characteristics of P(NDI2HD-T-S) Terpolymers in pristine films

\begin{tabular}{lcccc}
\hline Polymers & $\mathrm{d}^{100}(\mathrm{~nm})^{\mathrm{a}}$ & $\mathrm{L}_{c}^{100}(\mathrm{~nm})^{\mathrm{b}}$ & $\mathrm{d}^{010}(\mathrm{~nm})^{\mathrm{c}}$ & $\mathrm{L}_{c}{ }^{010}(\mathrm{~nm})^{\mathrm{d}}$ \\
\hline P1 & 2.24 & 9.63 & 0.415 & 1.52 \\
P2 & 2.23 & 9.86 & 0.411 & 1.55 \\
P3 & 2.22 & 13.14 & 0.408 & 1.59 \\
P4 & 2.21 & 13.77 & 0.405 & 1.61 \\
P5 & 2.22 & 15.39 & 0.405 & 1.66 \\
\hline
\end{tabular}

aDomain spacings of lamellar.

${ }^{\mathrm{b}}$ Correlation lengths of lamellar.

${ }^{c} \pi-\pi$ stacking in pristine films calculated from 2D GIXS in-plane and out-of-plane components, respectively.

${ }_{\pi-\pi}$ stacking crystals in pristine films determined from using the Scherrer equation.

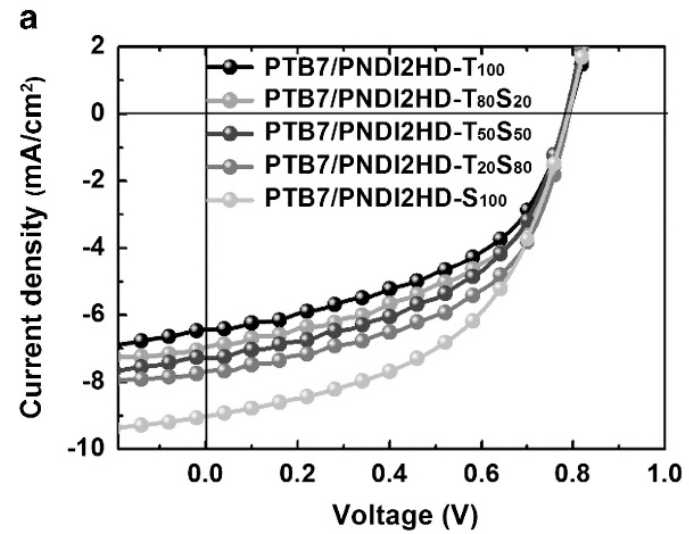

(P3), 13.77 (P4) and $15.39 \mathrm{~nm} \mathrm{(P5),} \mathrm{indicating} \mathrm{that} \mathrm{a} \mathrm{higher}$ selenophene content facilitates more developed crystalline structures. The preferred quinoidal form from selenophene can suppress chain rotation in the polymer backbone and promote higher intermolecular interactions. Therefore, a larger $L_{C}$ value with remarkable (h00) and $(00 l)$ reflection peaks was observed for P5. In addition, the correlation lengths of the $\pi-\pi$ stacking increased from 1.52 to $1.55,1.59,1.61$ and $1.66 \mathrm{~nm}$ for P1, P2, P3, P4 and P5, respectively.

\section{Photovoltaic and electrical properties}

To understand the correlations between the structural properties of the terpolymers and the performances of the devices, we fabricated P1-P5-based all-PSC devices. The all-PSCs were fabricated with an inverted structure consisting of ITO/ZnO/All polymer blend/ $/ \mathrm{MoO}_{3} /$ Ag, where the terpolymers (P1-P5) were used as polymer acceptors and PTB7 (shown in Figure 1) was used as a polymer donor. ${ }^{48}$ The donor:acceptor blend ratio $(\mathrm{w} / \mathrm{w})$ was optimized at 1.3:1, and DIO ( 1 vol\%) was added as a solvent additive. The films had similar thicknesses of $\sim 100 \mathrm{~nm}$. Figure 4 a shows the $J-V$ curves of the BHJtype all-PSCs based on P1-P5. The photovoltaic properties are summarized in Table 3. All of the devices exhibited similar opencircuit voltage $\left(V_{\mathrm{OC}}\right)$ values of c.a. 0.79 due to the similar LUMO energy levels of P1-P5. ${ }^{49,50}$ However, the PCE values of all-PSCs increased as follows: P1 $(2.50 \%)<\mathbf{P} 2(2.73 \%)<\mathbf{P 3}(2.87 \%)<\mathbf{P} 4$ $(3.21 \%)<$ P5 $(3.60 \%)$. The dramatic improvement in PCE was due to the larger $J_{S C}$ values (that is, $6.64(\mathbf{P 1}), 7.02(\mathbf{P} 2), 7.41(\mathbf{P} 3)$, 7.88 (P4) and $8.99 \mathrm{~mA} \mathrm{~cm}^{-2}$ (P5)) (Figure 4c). The external quantum efficiencies (EQEs) were measured for different all-PSCs

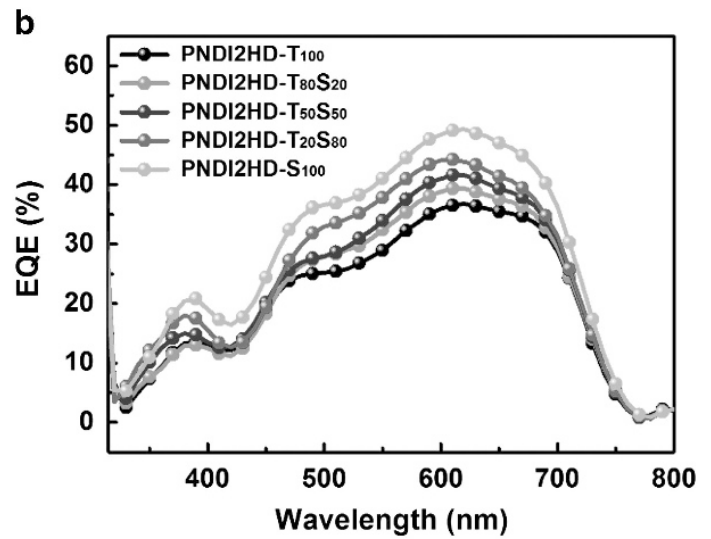

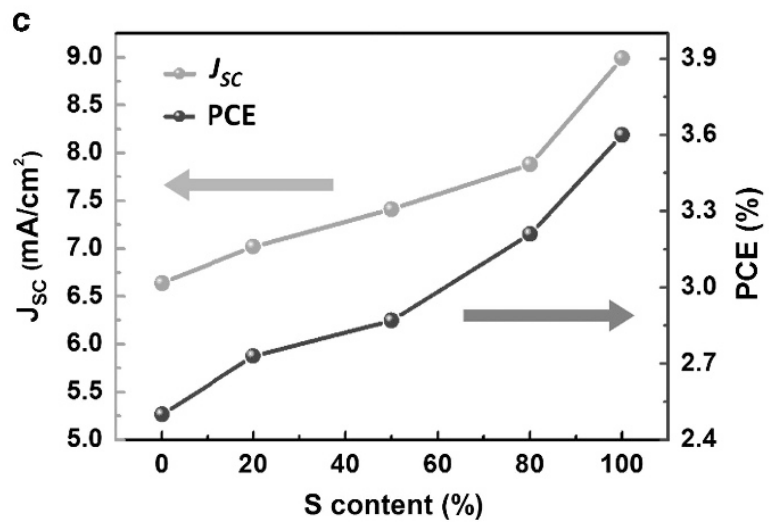

Figure 4 (a) Current-voltage ( $J-V$ characteristics of BHJ-type all-PSCs based on P1-P5. (b) EQE spectra of BHJ-type all-PSCs based on P1-P5. (c) JSC and PCE trends as a function of S content in the terpolymers. A full color version of this figure is available at Polymer Journal online. 
under optimized device conditions (Figure $4 \mathrm{~b}$ and Supplementary Table S3). The measured $J_{S C}$ values for the all-PSC devices were consistent (within $5 \%$ error) with the integrated $J_{S C}$ values obtained from the EQE spectra. As the selenophene content in the polymer increased, the EQE values were significantly enhanced from 500 to $700 \mathrm{~nm}$. For example, the EQE values at $620 \mathrm{~nm}$ improved 35\% from 36.7 (P1) to 49.4 (P5). These increases were primarily due to changes in the electrical properties (that is, charge transport and transfer) of the active layer rather than those in light absorption because the differences in the absorption spectra for P1-P5 devices were not significant (Supplementary Figure S4).

To further understand the trend in the PCE and $J_{S C}$ values, electron only space-charge-limited current (SCLC) devices for the pristine terpolymers were fabricated (Supplementary Figure S5). The electrononly SCLC devices consisted of ITO/ZnO/pristine terpolymer/LiF/Al. ${ }^{44}$ As the selenophene content increased, the electron mobility values $\left(\mu_{\mathrm{e}}\right)$ in the SCLC devices increased from $7.79 \times 10^{-6}(\mathbf{P 1})$ to $8.85 \times 10^{-6}$ (P2), $1.91 \times 10^{-5}(\mathbf{P 3})$ and $1.99 \times 10^{-5} \mathrm{~cm}^{2} \mathrm{~V}^{-1} \mathrm{~s}^{-1}$ (P4) (Table 3).

Table 3 Photovoltaic properties of the all-PSCs based on P1-P5 and electrical properties of pristine polymer films using the SCLC method

\begin{tabular}{lllcll}
\hline Polymers $^{\mathrm{a}}$ & PCE (\%) & $\mathrm{V}_{O C}(\mathrm{~V})$ & $\mathrm{J}_{S C}\left(\mathrm{~mA} \mathrm{~cm} \mathrm{~cm}^{-2}\right)$ & $F F$ & $\mu_{e}\left(\mathrm{~cm}^{2} \mathrm{~V}^{-1} \mathrm{~s}^{-1}\right)^{\mathrm{c}}$ \\
\hline P1 & $2.50(2.39)$ & 0.792 & 6.64 & 0.48 & $7.79 \times 10^{-6}$ \\
P2 & $2.73(2.63)$ & 0.794 & 7.02 & 0.49 & $8.85 \times 10^{-6}$ \\
P3 & $2.87(2.75)$ & 0.785 & 7.41 & 0.49 & $1.91 \times 10^{-5}$ \\
P4 & $3.21(3.07)$ & 0.793 & 7.88 & 0.51 & $1.99 \times 10^{-5}$ \\
P5 & $3.60(3.52)$ & 0.791 & 8.99 & 0.51 & $2.21 \times 10^{-5}$ \\
\hline
\end{tabular}

Abbreviations: FF, fill factor; PCE, power conversion efficiency; SCLC, space-charge-limited current.

aThe blend ratio $(\mathrm{w} / \mathrm{w})=1.3: 1$ with $\mathrm{DIO}(1 \mathrm{vol} \%)$ as additive. The device structure was ITO/ZnO/ All polymer blend/ $/ \mathrm{MoO}_{3} / \mathrm{Ag}$.

balues in brackets are averages of more than six devices.

cDetermined by SCLC method for pristine films.

The average values and s.d.'s are shown in Supplementary Information (Supplementary Table S3).
Finally, P5 exhibited the highest $\mu_{\mathrm{e}}$ value of $2.21 \times 10^{-5} \mathrm{~cm}^{2} \mathrm{~V}^{-1} \mathrm{~s}^{-1}$. The increased electron mobility was due to the intermolecular attractions of the Se atoms and the enhanced rigidity of the polymer backbone, which was confirmed by the GIXS measurements. ${ }^{36,42}$ In addition, the increasing tendency toward electron mobility was in good agreement with the PCE enhancement in the P1-P5 all-PSCs, suggesting that the enhanced charge mobility could be one of the main reasons for the enhanced $J_{S C}$ values of the all-PSCs.

\section{Blend morphology}

To elucidate the effect of the selenophene content on the BHJ blend morphologies of the active layers, AFM analysis was performed. Because the exciton diffusion lengths for semi-conducting polymers can be as short as a few nanometers, ${ }^{51}$ the polymer blend in the active layer must be phase separated within on a tens of nanometer length scale to ensure a large interfacial area between the polymer donor and acceptor. As shown in Figure 5, all of the blend films exhibited root mean square roughness values in the range of $0.61-0.88 \mathrm{~nm}$. In addition, bicontinuous and uniformly phase-separated microstructures within a length scale of tens of nanometers were observed for all of the blend systems, which is favorable for efficient charge separation. Interestingly, the AFM images indicated that the variation in the selenophene content in the polymers significantly influenced fibril formation in the blend film while a desirable well-mixed phase was maintained. In particular, the P5 film exhibited the most distinct fibril structures, which is in agreement with the GIXS results. Therefore, P5, which had the highest selenophene content, produced all-PSCs with higher PCE values due to the higher electron mobility through the well-developed fibril structures. ${ }^{36,52}$ In addition, the polymer packing structure and its orientation at the polymer donor/acceptor interface may be influenced by the introduction of selenophene in the polymer backbone, which could produce important contributions to the photovoltaic performance. ${ }^{53}$ Therefore, we are in the process of
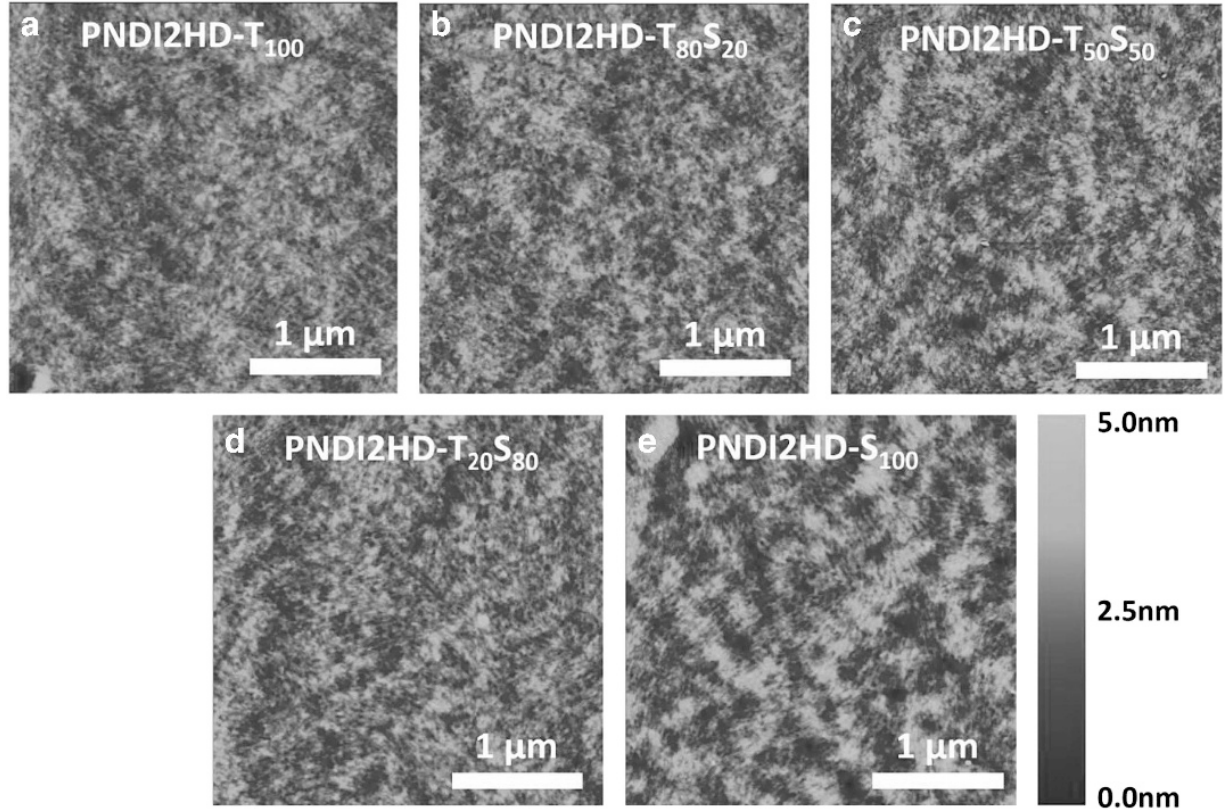

Figure 5 AFM images of the P1-P5 blend films with PTB7. Root mean square roughness of the film was (a) 0.61(P1), (b) 0.68 (P2), (c) 0.79 (P3), (d) 0.69 (P4) and (e) $0.88 \mathrm{~nm}$ (P5). The scale bars represent $1 \mu \mathrm{m}$. A full color version of this figure is available at Polymer Journal online. 
elucidating the packing structure and orientation of the terpolymers at the donor/acceptor interface.

\section{CONCLUSIONS}

A new series of $\mathrm{P}(\mathrm{NDI} 2 \mathrm{HD}-\mathrm{T}-\mathrm{S})$ terpolymers (P1-P5) with different $\mathrm{T} / \mathrm{S}$ compositions was successfully synthesized. The crystalline behaviors of the terpolymers were systematically tuned in terms of the T/S composition, and the composition effects on their optical, electrochemical, electrical and photovoltaic properties were investigated. The incorporation of a higher selenophene content induced stronger crystalline behavior (larger $L_{C}$ value and more-developed fibril structure) of the terpolymers, leading to significantly enhanced electron mobility. This beneficial feature, which was due to the higher selenophene content, resulted in a significant increase in the PCE values from 2.50 (P1) to $3.60 \%$ (P5). Therefore, our results highlight the importance of a terpolymer approach for controlling the intermolecular assembly of polymers and promoting their electron mobility, and our results provide important guidelines for the design of n-type polymer acceptors for high-performance all-PSCs.

\section{CONFLICT OF INTEREST}

The authors declare no conflict of interest.

\section{ACKNOWLEDGEMENTS}

This research was supported by the New and Renewable Energy Program of KETEP Grant (20133030000130, 20133030011330), which was funded by the Ministry of Trade, Industry and Energy, Republic of Korea. This research was supported by the Research Projects of the KAIST-KUSTAR and the CRH (Climate Change Research Hub) of KAIST.

1 Ashraf, R. S., Meager, I., Nikolka, M., Kirkus, M., Planells, M., Schroeder, B. C., Holliday, S., Hurhangee, M., Nielsen, C. B., Meager, I., Nikolka, M., Kirkus, M., Planells, M., Schroeder, B. C., Holliday, S., Hurhangee, M., Nielsen, C. B., Sirringhaus, H., McCulloch, I., Sirringhaus, H. \& McCulloch, I. Chalcogenophene comonomer comparison in small ban d gap diketopyrrolopyrrole-based conjugated polymers for high-performing field-effect transistors and organic solar cells. J. Am. Chem. Soc. 137, 1314-1321 (2015).

2 He, Z., Zhong, C., Su, S., Xu, M., Wu, H. \& Cao, Y. Enhanced power-conversion efficiency in polymer solar cells using an inverted device structure. Nat. Photonics 6, 593-597 (2012).

3 Zhong, H., Li, Z., Deledalle, F., Fregoso, E. C., Shahid, M., Fei, Z., Nielsen, C. B., Yaacobi-Gross, N., Rossbauer, S., Anthopoulos, T. D., Durrant, J. R. \& Heeney, M. Fused dithienogermolodithiophene low band gap polymers for high-performance organic solar cells without processing additives. J. Am. Chem. Soc. 135, 2040-2043 (2013).

4 Ye, L., Zhang, S., Zhao, W., Yao, H. \& Hou, J. Highly efficient 2D-conjugated benzodithiophene-based photovoltaic polymer with linear alkylthio side chain. Chem. Mater. 26, 3603-3605 (2014).

5 Cabanetos, C., El Labban, A., Bartelt, J. A., Douglas, J. D., Mateker, W. R., Frechet, J. M., McGehee, M. D. \& Beaujuge, P. M. Linear side chains in benzo[1,2-b:4,5-b'] dithiophene-thieno[3,4-c]pyrrole-4,6-dione polymers direct self-assembly and solar cell performance. J. Am. Chem. Soc. 135, 4656-4659 (2013).

6 Subbiah, J., Purushothaman, B., Chen, M., Qin, T., Gao, M., Vak, D., Scholes, F. H., Chen, X., Watkins, S. E., Wilson, G. J., Holmes, A. B., Wong, W. W. \& Jones, D. J. Organic solar cells using a high-molecular-weight benzodithiophene-benzothiadiazole copolymer with an efficiency of 9.4\%. Adv. Mater. 27, 702-705 (2015).

7 Nguyen, T. L., Choi, H., Ko, S. J., Uddin, M. A., Walker, B., Yum, S., Jeong, J. E., Yun, M. H., Shin, T. J., Hwang, S., Kim, J. Y. \& Woo, H. Y. Semi-crystalline photovoltaic polymers with efficiency exceeding $9 \%$ in a $300 \mathrm{~nm}$ thick conventional singlecell device. Energy Environ. Sci. 7, 3040-3051 (2014).

8 Huo, L., Liu, T., Sun, X., Cai, Y., Heeger, A. J. \& Sun, Y. Single-junction organic solar cells based on a novel wide-bandgap polymer with efficiency of $9.7 \%$. Adv. Mater. 27, 2938-2944 (2015).

9 Kim, K.-H., Kang, H., Nam, S. Y., Jung, J., Kim, P. S., Cho, C.-H., Lee, C., Yoon, S. C. \& Kim, B. J. Facile synthesis ofo-Xylenyl fullerene multiadducts for high open circuit voltage and efficient polymer solar cells. Chem. Mater. 23, 5090-5095 (2011).

$10 \mathrm{He}, \mathrm{Y}$. J. \& Li, Y. F. Fullerene derivative acceptors for high performance polymer solar cells. Phys. Chem. Chem. Phys. 13, 1970-1983 (2011).

11 Anctil, A., Babbitt, C. W., Raffaelle, R. P. \& Landi, B. J. Material and energy intensity of fullerene production. Environ. Sci. Technol. 45, 2353-2359 (2011).
12 Jorgensen, M., Norrman, K., Gevorgyan, S. A., Tromholt, T., Andreasen, B. \& Krebs, F. C. Stability of polymer solar cells. Adv. Mater. 24, 580-612 (2012).

13 Lipomi, D. J., Chong, H., Vosgueritchian, M., Mei, J. \& Bao, Z. Toward mechanically robust and intrinsically stretchable organic solar cells: evolution of photovoltaic properties with tensile strain. Sol. Energy Mater. Sol. Cells 107, 355-365 (2012).

14 Savagatrup, S., Printz, A. D., O'Connor, T. F., Zaretski, A. V., Rodriquez, D., Sawyer, E. J., Rajan, K. M., Acosta, R. I., Root, S. E. \& Lipomi, D. J. Mechanical degradation and stability of organic solar cells: molecular and microstructural determinants. Energy Environ. Sci. 8, 55-80 (2015).

15 Kim, T., Kim, J. H., Kang, T. E., Lee, C., Kang, H., Shin, M., Wang, C., Ma, B., Jeong, U., Kim, T. S. \& Kim, B. J. Flexible, highly efficient all-polymer solar cells. Nat. Commun 6, 8547 (2015).

16 Kang, H., Uddin, M. A., Lee, C., Kim, K. H., Nguyen, T. L., Lee, W., Li, Y., Wang, C., Woo, H. Y. \& Kim, B. J. Determining the role of polymer molecular weight for highperformance all-polymer solar cells: its effect on polymer aggregation and phase separation. J. Am. Chem. Soc. 137, 2359-2365 (2015).

17 Zhou, E., Cong, J., Hashimoto, K. \& Tajima, K. Control of miscibility and aggregation via the material design and coating process for high-performance polymer blend solar cells. Adv. Mater. 25, 6991-6996 (2013).

18 Kang, H., Kim, K.-H., Choi, J., Lee, C. \& Kim, B. J. High-performance all-polymer solar cells based on face-on stacked polymer blends with low interfacial tension. ACS Macro Lett. 3, 1009-1014 (2014).

19 Mu, C., Liu, P., Ma, W., Jiang, K., Zhao, J., Zhang, K., Chen, Z., Wei, Z., Yi, Y., Wang, J., Yang, S., Huang, F., Facchetti, A., Ade, H. \& Yan, H. High-efficiency all-polymer solar cells based on a pair of crystalline low-bandgap polymers. Adv. Mater. 26, 7224-7230 (2014).

20 Mori, D., Benten, H., Okada, I., Ohkita, H. \& Ito, S. Low-bandgap donor/acceptor polymer blend solar cells with efficiency exceeding 4\%.Adv. Energy Mater. 4, 1301006 (2014)

21 Lee, C., Kang, H., Lee, W., Kim, T., Kim, K. H., Woo, H. Y., Wang, C. \& Kim, B. J. Highperformance all-polymer solar cells via side-chain engineering of the polymer acceptor: the importance of the polymer packing structure and the nanoscale blend morphology. Adv. Mater. 27, 2466-2471 (2015).

22 Earmme, T., Hwang, Y. J., Murari, N. M., Subramaniyan, S. \& Jenekhe, S. A. Allpolymer solar cells with $3.3 \%$ efficiency based on naphthalene diimide-selenophene copolymer acceptor. J. Am. Chem. Soc. 135, 14960-14963 (2013).

23 Earmme, T., Hwang, Y. J., Subramaniyan, S. \& Jenekhe, S. A. All-polymer bulk heterojuction solar cells with $4.8 \%$ efficiency achieved by solution processing from a cosolvent. Adv. Mater. 26, 6080-6085 (2014).

24 Jung, I. H., Lo, W.-Y., Jang, J., Chen, W., Zhao, D., Landry, E. S., Lu, L., Talapin, D. V. \& Yu, L. Synthesis and search for design principles of new electron accepting polymers for all-polymer solar cells. Chem. Mater. 26, 3450-3459 (2014).

25 Deshmukh, K. D., Qin, T., Gallaher, J. K., Liu, A. C. Y., Gann, E., O'Donnell, K., Thomsen, L., Hodgkiss, J. M., Watkins, S. E. \& McNeill, C. R. Performance, morphology and photophysics of high open-circuit voltage, low band gap all-polymer solar cells. Energy Environ. Sci. 8, 332-342 (2015).

26 Mori, D., Benten, H., Okada, I., Ohkita, H. \& Ito, S. Highly efficient charge-carrier generation and collection in polymer/polymer blend solar cells with a power conversion efficiency of 5.7\%. Energy Environ. Sci. 7, 2939-2943 (2014).

27 Facchetti, A. Polymer donor-polymer acceptor (all-polymer) solar cells. Mater. Today 16, 123-132 (2013).

28 Yan, H., Chen, Z., Zheng, Y., Newman, C., Quinn, J. R., Dotz, F., Kastler, M. \& Facchetti, A. A high-mobility electron-transporting polymer for printed transistors. Nature 457, 679-686 (2009).

29 Choi, J., Kim, K.-H., Yu, H., Lee, C., Kang, H., Song, I., Kim, Y., Oh, J. H. \& Kim, B. J. Importance of electron transport ability in naphthalene diimide-based polymer acceptors for high-performance, additive-free, all-polymer solar cells. Chem. Mater. 27, 5230-5237 (2015).

30 Ye, L., Jiao, X., Zhou, M., Zhang, S., Yao, H., Zhao, W., Xia, A., Ade, H. \& Hou, J. Manipulating aggregation and molecular orientation in all-polymer photovoltaic cells. Adv. Mater. 27, 6046-6054 (2015).

31 Dai, S., Cheng, P., Lin, Y., Wang, Y., Ma, L., Ling, Q. \& Zhan, X. Perylene and naphthalene diimide polymers for all-polymer solar cells: a comparative study of chemical copolymerization and physical blend. Polym. Chem. 6, 5254-5263 (2015).

32 Hwang, Y. J., Earmme, T., Courtright, B. A., Eberle, F. N. \& Jenekhe, S. A. n-Type semiconducting naphthalene diimide-perylene diimide copolymers: controlling crystallinity, blend morphology, and compatibility toward high-performance all-polymer solar cells. J. Am. Chem. Soc. 137, 4424-4434 (2015).

33 Kozycz, L. M., Gao, D., Tilley, A. J. \& Seferos, D. S. One donor-two acceptor (D-A1)-(DA2) random terpolymers containing perylene diimide, naphthalene diimide, and carbazole units. J. Polym. Sci. A Polym. Chem. 52, 3337-3345 (2014).

34 Kang, T. E., Cho, H. -H., Kim, H. j., Lee, W., Kang, H. \& Kim, B. J. Importance of optimal composition in random terpolymer-based polymer solar cells. Macromolecules 46, 6806-6813 (2013).

35 Kang, T. E., Kim, K.-H. \& Kim, B. J. Design of terpolymers as electron donors for highly efficient polymer solar cells. J. Mater. Chem. A 2, 15252 (2014).

36 Kim, K.-H., Park, S., Yu, H., Kang, H., Song, I., Oh, J. H. \& Kim, B. J. Determining optimal crystallinity of diketopyrrolopyrrole-based terpolymers for highly efficient polymer solar cells and transistors. Chem. Mater. 26, 6963-6970 (2014). 
37 Song, J. S., Zhang, C., Li, C. H., Li, W. W., Qin, R. P., Li, B. S., Liu, Z. P. \& Bo, Z. S. Conjugated polymers with broad absorption: synthesis and application in polymer solar cells. J. Polym. Sci. A Polym. Chem. 48, 2571-2578 (2010).

38 Lee, J. W., Ahn, H. \& Jo, W. H. Conjugated random copolymers consisting of pyridine- and thiophene-capped diketopyrrolopyrrole as co-electron accepting units to enhance both JSC and VOC of polymer solar cells. Macromolecules 48, 7836-7842 (2015)

39 Kim, A., Lee, D. H., Um, H. A., Shin, J., Cho, M. J. \& Choi, D. H. Tunable light harvesting properties of a highly crystalline alternating terpolymer for high-performing solar cells. Polym. Chem. 6, 5478-5486 (2015).

40 Patra, A. \& Bendikov, M. Polyselenophenes. J. Mater. Chem. 20, 422-433 (2010).

41 Wijsboom, Y. H., Patra, A., Zade, S. S., Sheynin, Y., Li, M., Shimon, L. J. \& Bendikov, M. Controlling rigidity and planarity in conjugated polymers: poly(3,4-ethylenedithioselenophene). Angew. Chem. Int. Ed. 48, 5443-5447 (2009).

42 Lee, J., Han, A. R., Kim, J., Kim, Y., Oh, J. H. \& Yang, C. Solution-processable ambipolar diketopyrrolopyrrole-selenophene polymer with unprecedentedly high hole and electron mobilities. J. Am. Chem. Soc. 134, 20713-20721 (2012).

43 Hwang, Y. J., Courtright, B. A., Ferreira, A. S., Tolbert, S. H. \& Jenekhe, S. A. 7.7\% Efficient all-polymer solar cells. Adv. Mater. 27, 4578-4584 (2015).

44 Hwang, Y. J., Earmme, T., Subramaniyan, S. \& Jenekhe, S. A. Side chain engineering of n-type conjugated polymer enhances photocurrent and efficiency of all-polymer solar cells. Chem. Commun. 50, 10801-10804 (2014).

45 Cho, C. H., Kang, H., Kang, T. E., Cho, H. H., Yoon, S. C., Jeon, M. K. \& Kim, B. J. Controlling side-chain density of electron donating polymers for improving their packing structure and photovoltaic performance. Chem. Commun. 47, 3577-3579 (2011).
46 Steyrleuthner, R., Di Pietro, R., Collins, B. A., Polzer, F., Himmelberger, S., Schubert, M., Chen, Z., Zhang, S., Salleo, A., Ade, H., Facchetti, A. \& Neher, D. The role of regioregularity, crystallinity, and chain orientation on electron transport in a highmobility n-type copolymer. J. Am. Chem. Soc. 136, 4245-4256 (2014).

47 Rivnay, J., Mannsfeld, S. C., Miller, C. E., Salleo, A. \& Toney, M. F. Quantitative determination of organic semiconductor microstructure from the molecular to device scale. Chem. Rev. 112, 5488-5519 (2012).

48 Liang, Y., Xu, Z., Xia, J., Tsai, S. T., Wu, Y., Li, G., Ray, C. \& Yu, L. For the bright futurebulk heterojunction polymer solar cells with power conversion efficiency of $7.4 \%$. Adv. Mater. 22, E135-E138 (2010).

49 Brabec, C. J., Cravino, A., Meissner, D., Sariciftci, N. S., Fromherz, T., Rispens, M. T., Sanchez, L. \& Hummelen, J. C. Origin of the open circuit voltage of plastic solar cells. Adv. Funct. Mater. 11, 374-380 (2001).

50 Chen, H.-Y., Hou, J., Zhang, S., Liang, Y., Yang, G., Yang, Y., Yu, L., Wu, Y. \& Li, G. Polymer solar cells with enhanced open-circuit voltage and efficiency. Nat. Photonics $\mathbf{3}$, 649-653 (2009).

51 Menke, S. M. \& Holmes, R. J. Exciton diffusion in organic photovoltaic cells. Energy Environ. Sci. 7, 499-512 (2014).

52 Li, W., Hendriks, K. H., Furlan, A., Roelofs, W. S., Meskers, S. C., Wienk, M. M. \& Janssen, R. A. Effect of the fibrillar microstructure on the efficiency of high molecular weight diketopyrrolopyrrole-based polymer solar cells. Adv. Mater. 26, 1565-1570 (2014).

53 Schubert, M., Collins, B. A., Mangold, H., Howard, I. A., Schindler, W., Vandewal, K., Roland, S., Behrends, J., Kraffert, F., Steyrleuthner, R., Chen, Z., Fostiropoulos, K., Bittl, R., Salleo, A., Facchetti, A., Laquai, F., Ade, H. W. \& Neher, D. Correlated donor/ acceptor crystal orientation controls photocurrent generation in all-polymer solar cells. Adv. Funct. Mater. 24, 4068-4081 (2014).

Supplementary Information accompanies the paper on Polymer Journal website (http://www.nature.com/pj) 